NBER WORKING PAPER SERIES

\title{
PAYING THE PIPER, CALLING THE TUNE: IMPLICATIONS OF CHANGES \\ IN REIMBURSEMEN'T
}

Victor R. Fuchs

Working Paper No. 1605

NATIONAL BUREAU OF ECONOMIC RESEARCH 1050 Massachusetts Avenue

Cambridge, MA 02138

April 1985

Financial support from The Robert Wood Johnson Foundation and the research assistance of Leslie Perreault are gratefully acknowledged. The research reported here is part of the NBER's research program in Health Economics and project in Government, Budget. Any opinions expressed are those of the zuthor and not those of the National Bureau of Economic Research. 


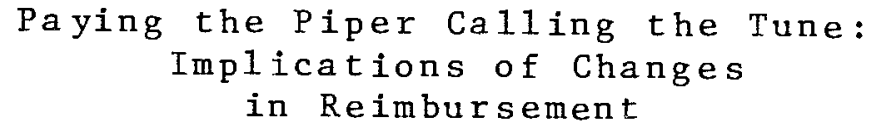

AB S TRACT

The United States is in the midst of a revolution in health care finance, the third since the end of World War II. Medicare's prospective payment system (PPS) based on diagnosis-related groups (DRGs), the State of California's hospital-specific contracts for Medi-Cal patients, deductibles and coinsurance, health maintenance organizations (HMOS), and preferred provider organizations (PPOs) are among the best known symbols of the new era in health care finance. This paper analyzes the economic factors responsible for innovations in reimbursement, discusses the distinguishing characteristics of the new methods, and examines their potential impact on hospitals, physicians, nurses, and patients. The paper concludes by considering some fundamental problems of public policy with respect to health care.

Victor R. Fuchs

National Bureau of Economic Research 204 Junipero Serra Boulevard

Stanford, CA 94305

415/326-7639 
PAYING THE PIPER, CAL.LING THE TUNE:

IMPLICATIONS OF CHANGES IN REIMBURSEMENT'

Victor R. Fuchs

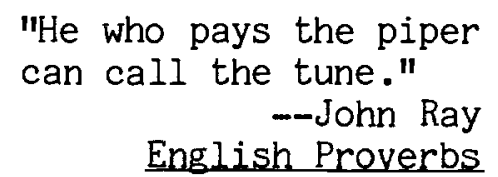

The financing of health care in the United States has undergone three revolutions since the end of World War II. First there was the extraordinarily rapid diffusion of private health insurance between 1945 and 1960. In only 15 years the number of persons with hospital insurance jumped from 32 million to 122 million, and the number with physician expense protection soared from less than 5 million to more than 83 million. Second, there was the 1965 legislation that created Medicare and Medicaid. This stroke of the pen provided substantial health insurance coverage to many additional millions of Americans among the elderly and poor.

The third major change began tentatively in the 1970s when a few states began experimenting with regulation of hospital reimbursement. This movement accelerated in the early 1980 s as both the private and public sectors embraced large-scale, radical alterations in the reimbursement of hospitals and physicians. Medicare's prospective payment system (PPS) based on diagnosisrelated groups (DRGs), the State of California's hospitalspecific contracts for Medi-Cal patients, deductibles and 
coinsurance, health maintenance organizations (HMOS), and preferred provider organizations (PPOs) are among the best known symbols of a new era in health care finance.

This third transformation is more difficult to define than the previous two, and it is far from completed. It may, however, prove to be the most revolutionary of the three. Certainly from the point of view of health care providers, the new methods of reimbursement have implications far greater than those stemming from the spread of private insurance or the introduction of Medicare and Medicaid. The latter two movements increased demand for medical care, regularized payment and made it more secure, and increased equality of access. Neither movement, however, threatened the traditional system of organization and delivery of care. Private insurance companies were extremely loathe to challenge the behavior of physicians or hospitals, and the Medicare and Medicaid legislation stated specifically that there was to be no interference with traditional practice.

The current revolution in reimbursement starts from a different premise. The "third parties" (government and business) who have been "paying the piper" have decided to "call the tune." Far from promising not to change the system, they frequently have change as a major objective. The primary purpose of this paper is to consider the economic and ethical implications of these changes. It will look at possible effects on patients as well as providers and on medical education and research as well as on patient care. Implications for efficiency in the allocation of resources, for distributional equity, and for other ethical 
problems will also be discussed. The paper begins with an analysis of why these changes have been introduced, followed by a brief discussion of their distinguishing characteristics. The next section examines their potential impact, and the final section highlights the fundamental policy issues that must be addressed by any system of health care finance. 


\section{Recent Changes}

Economic Background

Health policy traditionally encompasses three major areas: access to care, the health of the population, and the cost of care. In the 1950s and 1960s the first two concerns were dominant. Numerous health policy initiatives ranging from expansion of medical education and research to the introduction of Medicare and Medicaid were undertaken with the goals of eliminating barriers to access and improving the health of the population. Costs were secondary, and frequently were not considered at all.

In these two primary areas of concern, considerable progress was achieved. Disparities in access to care across income groups and between whites and nonwhites were sharply reduced. Delays in admission to hospitals were virtually eliminated; indeed, most hospitals now report excess capacity. As surpluses of medical and surgical specialists in the larger cities developed, more physicians began to locate in smaller cities and towns. Many of these changes are directly attributable to specific health policy initiatives.

The past twenty years have also witnessed extraordinary improvements in the health of the population, including a 60 percent reduction in infant mortality (to 10 per 1,000 live births) and very large declines in age-adjusted death rates from influenza and pneumonia, heart disease, and stroke. Unlike the gains in access, it is more difficult to tie these advances in 
health to specific policies or programs, but it is likely that thenumerous public policy initiatives played some positive role. As these gains were unfolding in the 1970s, the nation became increasingly aware of the high and rapidly rising cost of medical care. The health sector, which in 1950 had used only 4.4 percent of the nation's output, had grown to 6.1 percent by 1965 , to 9.4 percent by 1980 , and to 10.8 percent by 1983 . The cost problem, which had been building throughout the period, became critical in the late 1970 s and the early 1980s because the economy as a whole grew very slowly while health expenditures kept increasing at an extremely rapid pace. Figure 1 shows that the annual percentage changes in gross national product and health expenditures tend to follow the same pattern. (Both series have been adjusted for inflation and population growth and smoothed with a five-year moving average.) In the late 1970s and early 1980s, however, the rate of growth of the GNP fell to less than one percent per annum while real health expenditures per capita continued to increase at more than four percent. The health care system is like an 80,000 ton ocean liner going full speed ahead; it can't be turned around on a dime. But sooner or later health spending must reflect the country's underlying economic capacity.

The problem can be seen even more clearly in Figure 2, which shows the difference between changes in health spending and changes in the GNP. This "gap" is a measure of the rate at which labor and capital flow to the heelth sector awa from the rest of the economy. When this gap reached 4 percent per annum in the late 1970s and early 1980s, the heal th sector's share of GNP grew 
Figure 1

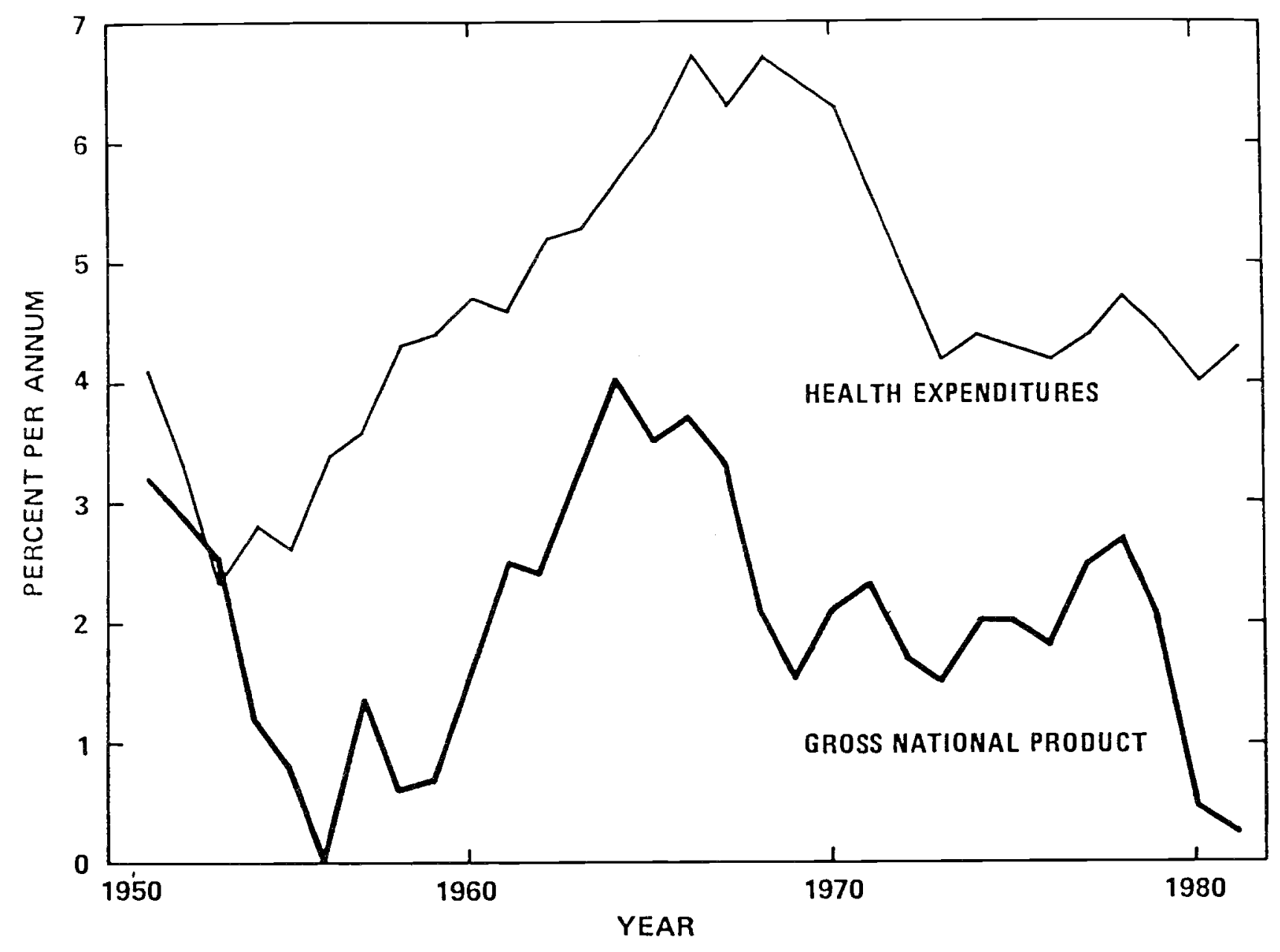

Annual percentage change in gross national product and health expenditures, adjusted for inflation and population growth, 1951-1981 (five-year moving average) 
Figure 2

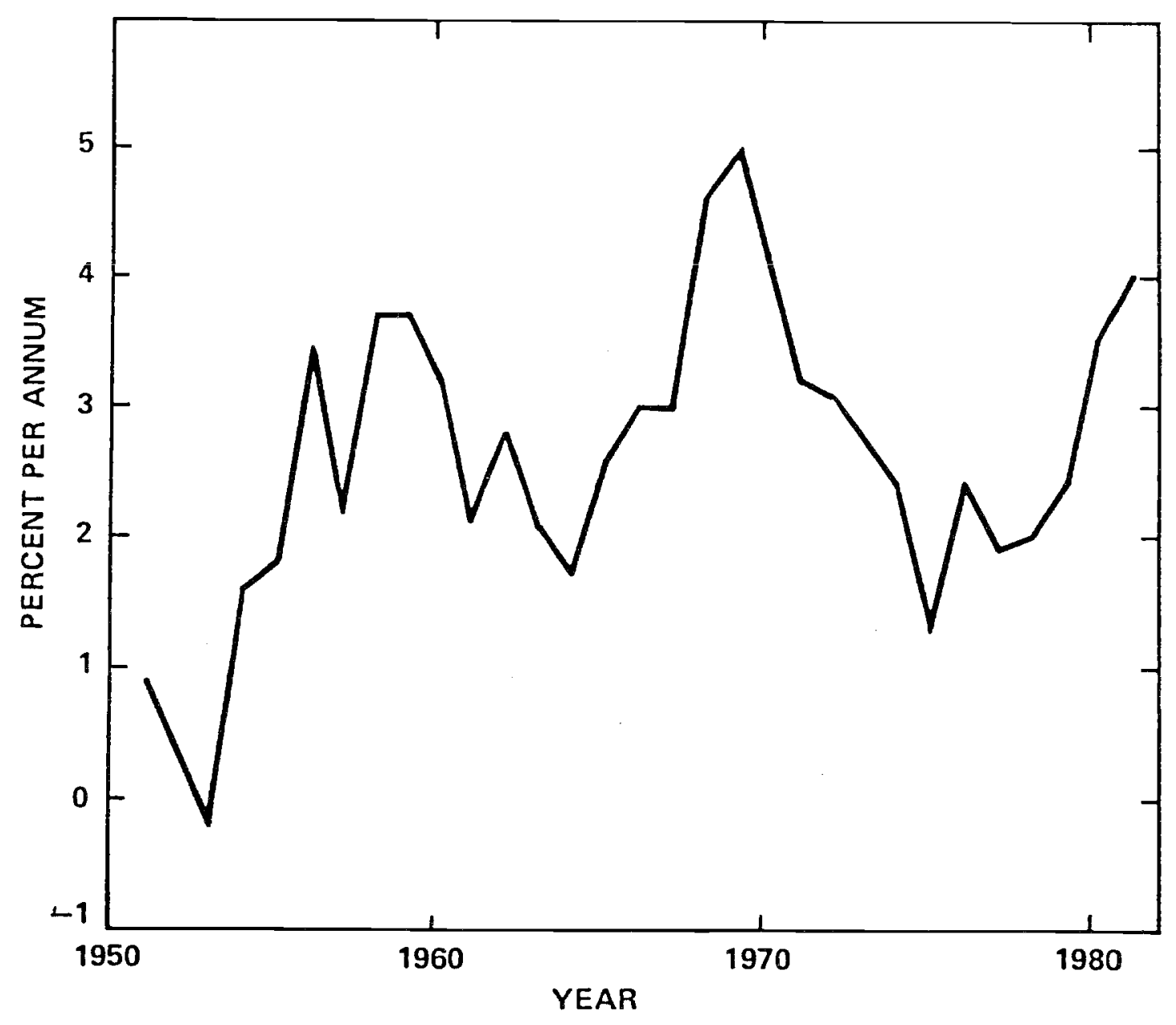

Difference in annual percentage change, health expenditures minus gross national product, 1951-1981 (five-year moving average) 
from 9 percent to 10 percent in less than three years.

If the overall economy resumes and maintains a more rapid rate of growth, as it did in 1983 and 1984, the gap should decrease. But there is a second problem with respect to cost: the size of the gap in the long run. Over the past 30 years the gap has averaged 2.7 percent per annum. If a gap of this magnitude were to continue for another 30 years, health spending would grow to over 20 percent of the gross national product. It seems highly likely that the other sectors of the economy will make strenuous efforts to prevent that from happening.

Resistance to the expansion of the health sector mounts because the larger that sector is, the more it takes away from other sectors when its rate of growth exceeds that of the economy as a whole. When the health sector was only 5 percent of the Gross National Product, the large gap increased its share to 10 percent, thus taking away five percentage points from the rest of the economy. But now that the share is 10 percent of GNP, the same gap over the same number of years would raise the share to almost 20 percent, thus taking away 10 percentage points from the rest of the economy. The larger any sector is relative to the total economy, the more difficult it is for it to grow faster than the total. Even a two percent gap for 30 years would put health at 17 percent of the GNP. But a smaller gap means a slower rate of growth for the health sector unless the GNP grows very rapidly.

These overall macroeconomic considerations have had special force within the federal government and have contributed to a 
sense of panic, as shown in Table 1. We see in the fifth row the familiar increase in health spending as a percentage of GNP. We also can note the federal government's increased share of health spending (row 6) and perhaps most important of all, the rise in federal health spending as a share of total federal spending (row 7). The federal government faces a tremendous deficit, now, and for several years ahead. It must hold down spending, or raise taxes appreciably. One result is a strenuous effort to curb federal spending for health.

The private sector also feels the squeeze, as may be seen in Table 2, which highlights the growth of private health insurance premiums. Increases in these premiums in the short run are paid mostly by business corporations as employee benefits. In that sense, in the short run they come out of profits. We can see that in 1950 these premiums were less than six percent of profits, but by 1980 they were 40 percent. In the long run, these payments come out of the real compensation of employees (in the form of lower wages or higher prices). It is also relevant, therefore, to note how rapidly these premiums have risen as a share of disposable personal income. In short, there is widespread interest and concern about health spending because it looms so large in both public and private budgets.

To be sure, an increase in a sector's share of GNP need not automatically be cause for alarm. There is nothing sacred about five percent of GNP, or 10 percent. Why not 20 percent? In a dynamic market economy some sectors will grow and some will shrink as a result of changes in demand and supply, and if the health sector grows--so what? In general, economic theory 
TABLE 1. FEDERAL AND NATIONAL HEALTH EXPENDITURES, TOTAL FEDERAL OUTLAYS, AND GROSS NATIONAL PRODUCT

(three-year averages centered on selected years, 1950-1980; billions of 1983 dollars)

\begin{tabular}{lrrrrrrr}
\hline & 1950 & 1955 & 1960 & 1965 & 1970 & 1975 & 1980 \\
\hline & & & & & & & \\
& & & & & & \\
(1) Federal health expenditures & 6 & 7 & 9 & 16 & 42 & 63 & 87 \\
(2) National health expenditures & 52 & 63 & 84 & 119 & 176 & 228 & 302 \\
(3) Total federal outlays & 170 & 248 & 295 & 359 & 463 & 547 & 695 \\
(4) Gross national product & 1175 & 1404 & 1589 & 2015 & 2369 & 2686 & 3224 \\
(2) as percent of (4) & & & & & & & \\
(1) as percent of (2) & 4.4 & 4.5 & 5.3 & 5.9 & 7.4 & 8.5 & 9.4 \\
(1) as percent of (3) & 12.5 & 11.2 & 11.2 & 13.4 & 24.2 & 27.6 & 28.7 \\
\end{tabular}

\section{Sources:}

Council of Economic Advisors. 1984. Economic Report of the President. Washington, D.C.: U.S. Government Printing Office. Tables B-T and B-73.

Gibson, Robert M., Daniel R. Waldo, and Katharine R. Levit. 1983. "National Health Expenditures, 1982," Heal th Care Financing Review, Vol. 5(1) (Fa11). Baltimore, Md.: Health Care Financing Administration. Table 1. 
TABLE 2. HEALTH INSURANCE PREMIUMS, CORPORATE PROFITS, AND DISPOSABLE PERSONAL INCOME (three-year averages centered on selected years, 1950-1980; billions of 1983 dollars)

$\begin{array}{lllllll}1950 & 1955 & 1960 & 1965 & 1970 & 1975 & 1980\end{array}$

(1) Heal th insurance premiums $\begin{array}{lllllll}8 & 15 & 23 & 35 & 47 & 65 & 91\end{array}$

(2) Corporate profits before taxes $\begin{array}{lllllll}134 & 147 & 152 & 226 & 188 & 196 & 227\end{array}$

(3) Disposable personal income $\begin{array}{lllllll}833 & 975 & 1105 & 1382 & 1639 & 1879 & 2226\end{array}$
(1) as percent of (2)
5.
(1) as percent of (3)
$0.9 \quad 1.6$
15.4
15.425 .1
$32.9 \quad 40.0$
2.1
2.5
2.9
3.4
4.1

\section{Sources:}

Council of Economic Advisors. 1984. Economic Report of the President. Washington, D.C.: U.S. Government Printing 0ffice. Tables B-23 and B-82.

Health Insurance Association of America. 1982-1983. Source Book of Health Insurance Data. Washington, D.C.: Health Insurance Association of America. TabTe 3.1. 
supports this view--but there is something peculiar about health spending, namely the importance of third-party payment. Both theory and empirical research suggest that private and public insurance programs bias the system toward "over-utilization." When consumers pay for goods and services directly, they tend to balance the costs of what they buy against the benefits they expect to receive. When insurance is present, however, the patient will want, and the responsive physician will choose, an amount of care where the cost to society of the additional care exceeds the benefit to the patient. Deductibles and coinsurance can alleviate this problem a little, but most Americans want to be insured against large health care expenditures. Thus a fundamental problem of health care policy is how to provide insurance without pushing utilization far beyond the point where the additional benefit is equal to the additional cost. To summarize: recent changes in reimbursement primarily reflect a desire to curb spending--a desire that arises for three principal reasons. First, the slow growth of the economy in the late 1970s and early 1980s was not accompanied by an equivalent slowing in health spending. Thus the gap between the two growth rates became alarmingly large. Second, health spending now takes such a large fraction of public and private budgets, it is questionable whether even the average gap of the past three decades (about 2.7 percent per annum) can be sustained. Third, the large role played by third-party payment has raised doubts whether the benefits to patients from additional spending are equal to the cost to society of providing the additional care. 
A fourth reason, probably less important from a long-run perspective, is that the country is currently in a pause or even a retreat from the thrust toward more equal access to care. Some, but not all, of the cutbacks in funding and changes in methods of reimbursement can be interpreted as a weakening of the commitment to provide high quality care to the poor. This aspect will be discussed further in sections II and III.

\section{General Characteristics}

Significant changes in health care finance have occurred in almost every sector of the economy. The federal government has radically altered hospital reimbursement for Medicare patients; several state governments regulate hospital rates for all types of patients; other states have installed special cost containment programs for Medicaid patients; participation in health maintenance organizations has been growing at an unprecedentedly rapid rate; health care providers and health insurance companies are experimenting with a variety of new types of coverage which channel patients to "preferred providers" in exchange for discounts in fees and charges; and many conventional insurance policies are being changed to include larger deductibles and coinsurance.

With such a diverse set of changes under way, it is not easy to provide a brief summary of their characteristics. Indeed, apart from a desire to contain costs, there is probably no characteristic that is common to ald new programs. There are, however, a few features that are sufficiently general to warrant a brief discussion. 
1. Much of the recent emphasis is on changes that lower costs for specific payers. Many previous policy proposals were aimed at containing costs for the health care system as a whole, e.g., Alain Enthoven's Consumer Choice Health PIan, or President Carter's proposal to cap hospital expenditures. With the exception of the all-payer hospital regulations in a few states, this is not true of recent cost containment initiatives. For example, Medicare's Prospective Payment System is designed to lower costs for Medicare. The State of California's hospital specific contracts for Medi-Cal (Medicaid) patients is designed to save money for the government of California. The insurer initiated preferred provider organizations and prudent buyer plans are explicitly intended to lower costs for the initiators of these plans.

There may be nothing wrong with this competitive, individualistic approach. Indeed, it may be the only way to obtain rapid change in a system that previously seemed rooted in "business as usual." Ever since Adam Smith, economists have been intrigued by the observation that an individual "by pursuing his own interest . . frequently promotes that of the society more effectually than when he really intends to promote it" (Smith, 1776). Economists have also discovered, however, that the individualistic approach does not always lead to socially optimal results. Later in this paper we will consider some possible adverse consequences of a free market solution to problems of health insurance and health care. 
2. Payment for individual tests, visits, days in hospital, and the like are being replaced by global payments for an illness episode, a hospital admission, or for a year of care regardless of services used (capitation).

3. Reimbursement rates are set prospectively rather than retrospectively. This change is often described as the end of "cost based reimbursement," but that is not the most accurate description. Costs of production will continue to play a major role in the determination of health care prices, just as they do in virtually all markets, including the most competitive. What is disappearing is the willingness of payers to pay retrospectively based on cost rather than knowing in advance what the price will be. Buyers are now negotiating in advance for a particular package of services.

4. Consumers must make more choices and accept more financial responsibility for their choices. In the past, many employers offered a single health plan to their workers. Now it is not unusual for employees to choose among conventional reimbursement insurance, a closed panel prepaid group practice, a preferred provider plan, and still other forms of payment and organization. Moreover, within the conventional reimbursement mode there are frequently choices to be made about the size of the deductible and the percentage of coinsurance. Those consumers who choose a preferred provider plan frequently have the option to obtain care outside the plan if they are willing to pay a larger coinsurance percentage. 


\section{Implications of Recent Changes}

Just as it is difficult to generalize about the characteristics of recent changes in reimbursement, it is also difficult to generalize about their likely effects. Each innovation in organization and finance has its own special thrust and its own special economic and ethical implications. Furthermore, most of the changes are very recent; not enough time has elapsed to collect and analyze reliable measures of their impact. This section, therefore, is primarily speculative. I draw on economic theory to infer the likely effects of changes from retrospective to prospective payment and from reimbursement for individual services to global reimbursement. I also consider the implications of increased competition in insurance and medical care markets, and of greater use of deductibles and coinsurance on efficiency and equity. Inferences from theory are supplemented by the results of demonstrations and experiments in health care reform.

\section{Economic Implications}

The primary purpose of recent changes in organization and finance is to slow the rate of increase in health care spending. It seems likely that they will have this effect, at least in the short run. This will come about primarily because the incentives and constraints facing the key decision makers--physicians, hospital administrators, insurance buyers, and patients--will be different from those they faced in the past. 
Physicians. The most important impact on physicians will probably come from the shift to global forms of reimbursement. As long as physicians are reimbursed for each service individually, there is less reason for them to question the incremental value of each additional visit, test, X-ray, and the like. Global reimbursement for an episode of illness, however, or for a year of care regardless of services provided (as in capitation payment) will give physicians great incentive to consider the incremental value of what they do. Furthermore, as more physicians assume some financial responsibility for the hospital care, prescriptions, and other dimensions of care that they order, they will have greater incentive to question the value of that care.

The best example of this phenomenon is the lower hospital utilization in prepaid group practice plans [Luft, 1981]. In the past some skeptics argued that lower hospital utilization in Kaiser, the Group Health Cooperative, and other prepaid group practices was the result of patient differences. They claimed that patients who needed or wanted less hospitalization sought out the prepaid plans. However, a prospective, controlled experiment that randomly assigned patients to a prepaid plan or conventional insurance demonstrated the same difference in hospital utilization that was observed in less adequately controlled studies [Manning et al., 1984].

Hospital administrators. While there is no completely satisfactory model of a nonprofit hospital or of the behavior of hospital administrators, there are a few generalizations that command wide agreement. The primary job of a hospital 
administrator is to keep other people happy, or, if not happy, at least not too unhappy. The "other people" are the physicians who bring patients to the hospital, the patients themselves, the employees who work in the hospital, and the trustees who can hire and fire the administrator. Each of these constituencies has different and sometimes conflicting goals. The physician wants the hospital to have the most modern technical facilities, a large high-quality staff of nurses, technicians, and other personnel, and considerable excess capacity to reduce the possibility of delays in admission or services for the patient once admitted. The patients typically want high quality care and amenities; price is rarely of concern because hospital insurance is widespread and usually comprehensive. The nurses, technicians, and other employees want good wages and working conditions, and the opportunity to provide high quality care. The trustees typically want to be associated with a high quality hospital that delivers excellent care and that enjoys a good reputation in the community. The latter may entail providing care for those in need regardless of ability to pay. All groups want the hospital to remain solvent, but in the past that was usually taken for granted. Under the traditional system of retrospective reimbursement based on incurred costs, most of the pressures on the administrator were in the direction of improving quality regardless of the effect on cost. A reimbursement system such as Medicare's Prospective Payment System dramatically changes the balance of pressure. Under the new system there is a real prospect that the hospital will not have enough revenue to cover 
its costs. The need to stay solvent was always one of the implicit pressures on the administrator, but now it has become explicit. Physicians begin to realize that the increased cost of new equipment and additional personnel won't necessarily be matched by increased revenue; if the hospital is forced out of business it will not be there to receive their patients. The employees begin to realize that higher wages or greater fringe benefits cannot automatically be covered by higher charges. Faced with the prospect of deficits and even bankruptcy, the trustees start changing the questions they ask and the pressures they put on the administrator. There is nothing that can match red ink for attracting the attention of trustees of hospitals or other organizations.

Health insurance companies. Increased competition in health insurance markets will also tend to restrain the growth of expenditures for health care. Both public and private insurers are abandoning their laissez-faire attitude toward physicians and hospitals in two important ways: they are bargaining about price, and they are insisting on controls over utilization. Individual insurance companies now have little choice in the matter because if they do not move in a cost restraining direction they will lose out to those companies that do.

Patients. Those patients who continue to have "wall-towall" coverage under conventional insurance will continue to want "everything possible." An increasing proportion of patients, however, will be paying for some of their care directly, through deductibles and coinsurance. The basic law of demand says that an increase in the price of a commodity results in a decrease in the 
quantity demanded. The Rand health insurance experiment [Newhouse et al., 1981] demonstrated conclusively that medical care is not an exception. Families with complete insurance coverage (no deductibles or coinsurance) used substantially more physicians' services and had more hospital admissions than did families who had to pay for a portion of the bill at the time of utilization. The growing use of deductibles and coinsurance in private insurance and government programs is likely to decrease the demand for medical care. How this will affect the quantity and price of care will depend on the sensitivity of supply to price change. In the short run, when supply is likely to be quite inelastic, the decrease in demand will result in a small decrease in quantity and large downward pressure on price. In the long run, when supply is more elastic, the primary effect of a decrease in demand will be on quantity, with a smaller effect on price. All of the above assumes no shifting of demand. If suppliers, faced with decreasing demand, can in part offset the decrease by recommending more care, the declines in quantity and price will be smaller than otherwise. Global forms of reimbursement and direct controls on utilization, however, will tend to restrain the ability of suppliers to shift demand. Differential impacts. While the general effect of reimbursement changes is to restrain the growth of expenditures, the impact will vary for hospitals, physicians, and nurses. Most of the belt-tightening is likely to be felt by hospitals, for several reasons. First, it is tempting to try to control hospital costs because they are such a large part of the total (over 40 
percent) and have been rising especially rapidly. Second, it is easier to control payments to a few thousand hospitals than to hundreds of thousands of physicians. Third, most of the demand for hospital services is generated by physician decisions. As physicians begin to realize that money spent for hospital care is money that could be spent for their services, they are likely to hospitalize patients less. At first, it will be possible to do this without seriously jeopardizing patients' health, as has been demonstrated with shorter lengths of stay and ambulatory surgery. Hospitals are likely to try to adapt to cost controls and the decreased demand for in-patient care by diversifying into other activities, including "captive" physicians' groups, home health care services, and community-based health promotion activities. Although physicians collectively have the opportunity to protect their incomes by directing most of the restraint on spending toward hospitals, equipment manufacturers, and drug companies, they too will have to adapt in ways that many will find unpleasant. In particular, in order to cope with the new financial constraints physicians will probably have to give up some of their independence and autonomy. Increasingly they will feel the need to join group practices or other forms of organizations in order to be able to bargain with insurance companies and other purchasers of care. Also, they will increasingly feel the need for professional managers to help them function in a more competitive environment. In the process, some of their power and decision-making authority will be lost.

Changes in methods of hospital reimbursenent are also likely to affect the goals of the nursing profession. For instance, in 
the past many hospital nurses were working toward a goal of separate billing for their professional services. They believed that this approach would increase the prestige and status of nurses and result in greater economic return. Given the trend toward global reimbursement, however, either on a capitation or admission basis, there is no scope for separate billing by nurses. Indeed, separate billing by physicians may well be on its way out.

Another goal of hospital nurses in the past was to transfer to other personnel responsibilities that were considered peripheral to nursing, or were considered to be below their skill level. With a shrinkage in the demand for hospital care resulting from new reimbursement methods, however, nurses will become more concerned about protecting their jobs and may reverse these goals. In the future, more nurses are likely to argue that it is better to have most patient services provided by the same person--the professional nurse.

Longer run effects. While many of the changes in ways of thinking and behavior induced by the changes in incentives may be short-run or one-time, some effects will emerge only over a longer period of time and are likely to be cumulative. For instance, even in the short run physicians will have an incentive to consider the incremental value of services in relation to their incremental cost, but they may not know what the incremental value is. Over the longer run there is likely to be more research on these questions, both informally within health care institutions and more formally at medical schools and 
research organizations. Similarly, in the long run the education and training of physicians is likely to change to make them better able to evaluate and assimilate this type of research. To cite another example, in the short run hospital administrators may want to take account of marginal costs in their decisionmaking, but the relevant information may not be available. In the longer run these data will be developed and utilized.

Another likely long-run consequence is a shift in the character of innovative activity. Innovations in medical care, as in other fields, typically take one of two forms. There is "product" innovation that consists of the introduction of new services that increase the quality of care, e.g., organ transplants, neonatal intensive care. These innovations usually increase the cost of care but they allow physicians and other health professionals to deliver a superior product. The other kind of innovation is "process" innovation, e.g., automated testing. It enables health professionals to do what they have been doing but to do so at lower cost. There have always been both kinds of innovations, but in the past the retrospective cost-based reimbursement system tended to encourage product innovation that increases cost. In the future, with prospective, closed-end reimbursement methods, the emphasis is likely to switch to process innovation that lowers cost.

Distributional effects. One of the likely effects of the Medicare PPS is to redistribute resources among institutions and among regions of the country. The implications for efficiency and equity of this redistribution vary, depending upon the reasons 
for the original disparity in costs. Suppose Hospital A treats patients in DRG $X$ at an average cost of $\$ 5,000$ per admission, while Hospital $B$ has an average cost of $\$ 3,000$ for patients in the same DRG. Under the old system each hospital would be paid its cost. Under the new system each will get $\$ 4,000$, thus redistributing resources from $A$ to $B$. The evaluation of this redistribution depends critically on the reason for the difference in cost.

One possibility is that $B$ is simply more efficient than $A$, i.e., the patients are identical, input prices are identical, and patient outcomes are identical, but $B$ does a better job of producing care. In this case it is both efficient and equitable to redistribute resources, i.e., to reward the efficient and punish the inefficient.

A second possibility is that there is no difference in output, patient mix, or efficiency, but that Hospital A pays higher prices for its inputs. It may be, for example, that there is a strong union in A that has negotiated higher wages or that the administrators in $\mathrm{A}$ are paid higher salaries than the administrators in $B$. In that case there are no great efficiency gains in transferring resources, since there are no efficiency differences. The redistribution does seem to be equitable, however, unless the wage differential simply offsets a difference in the cost of living.

A third possibility is that the differences in costs are due to differences in output. Although the patient mix is the same, Hospital A uses more inputs to produce higher quality care, more 
amenities, and the like. In this case the redistribution may be judged equitable (there is nothing in the Medicare legislation to suggest that patients in Hospital A ought to get a higher standard of care than patients in Hospital B). The implications for efficiency are not as obvious, but the value of the marginal output of the additional resources is probably greater in B than in $\mathrm{A}$.

Still another possibility is that the difference in cost is the result of differences in patient mix within the DRG. To the extent that this is the source of the cost differential, there may be no gains to efficiency or equity in redistributing resources; there may even be losses. Teaching hospitals, for instance, claim that differences in patient mix contribute to their higher costs. Some studies suggest that education and research also raise costs in hospitals that carry on these activities.

Education and research. One special area of concern is the future of support for education and research. In the past some of the funding for these efforts probably came from reimbursement for patient care. The new methods of reimbursement are designed in part to do away with this type of cross-subsidization. The buyers of care are saying "We want to pay for only the care we use; if we want to support education and/or research, we will do that separately." It's always nice to know what you are paying for and not have to buy into "package" deals or "tie in" sales.

It is also desirable to distinguist between the funding of medical education (undergraduate and postgraduate) and the 
funding of research. In too many discussions these two activities are treated as if they were inextricably related. This may well be true with respect to the production of education and research, but it certainly need not be true of the funding. Indeed, economic theory suggests that they should be treated differently. Medical research often has large positive externalities, i.e., confers benefits on society as a whole that are far greater than the return to those carrying on the research. Because of these externalities the private market will do less research than is socially optimal. The case for government subsidy is very strong. With respect to medical education, the case for government subsidy is much weaker. Most of the benefits of this education are realized by those who receive the training. There is no obvious case for subsidization to achieve the socially optimal amount. As a matter of equity, society may want to help poor students obtain access to medical education but this can be accomplished through sharply focused loans and scholarships rather than general subsidies.

Hospital specialization. The new systems of reimbursement are likely to lead to hospitals specializing in the diagnosis and treatment of particular health problems. Such specialization would raise the quality of care and increase efficiency. Specialization, however, poses a problem for academic medical centers with traditional teaching programs. It would be more difficult to provide a complete educational experience for medical students in a specialized hospital; some changes in educational programs would be necessary. 
Specialization may also bring one type of payment system into conflict with another. For instance, the Medicare system based on DRGs clearly favors the growth of specialization, but the PPO systems would tend to lose bargaining power as a result of hospital specialization. Suppose the XYZ Corporation enters into a PPO arrangement with a local hospital to send all their employees to that hospital in exchange for a price discount and utilization controls. If the hospital becomes specialized in certain types of care, those employees who need other types of care will not be well served by the PPO system. The XYZ Corporation could presumably adapt by making arrangements with all the local hospitals, but then the PPO system loses some of its cutting edge.

Although many patients might benefit from the higher quality and lower costs resulting from hospital specialization, there will be disadvantages to patients as well. There are disadvantages to being hospitalized in an unfamiliar institution or in one that is inconveniently located. In a system of specialized hospitals patients will have to weigh these disadvantages against the advantages of receiving more specialized care.

Decrease in number of specialists. While hospitals are likely to become more specialized, the proportion of physicians who are specialists or subspecialists is likely to fall. Surgery is a good example. Under the traditional system of fee-forservice reimbursement with surgeons practicing alone or in small groups, the typical community has a large number of surgeons relative to the demand for operations. The average surgeon has a 
low workload, but high fees per procedure yield a good income.

The new reimbursement systems will shift medical practice toward large groups or other large-scale organized systems of care. As demonstrated by the Mayo $\mathrm{Cl}$ inic and Kaiser, these groups and systems take on only as many surgeons as are needed at a full workload for each surgeon. The ones so employed continue to earn a good income, but their implicit fee per procedure is much less than in traditional practice. The low workload-high fee pattern will cease to be economically viable for most surgeons, and young physicians will be less likely to enter surgery.

Surgeons are not the only ones who will be affected. Much the same story could be told about many internal medicine subspecialties, and much the same pattern of change will emerge. This decrease in the number of specialists who have small workloads in their specialty could simultaneously lower costs and raise the quality of care.

\section{Ethical Concerns}

The financing and delivery of health care has always posed ethical problems for health professionals and for society as a whole. Some of these problems will be exacerbated by the changes in reimbursement that are now under way, and new problems are likely to arise. They will be encountered at the level of the individual physician, among groups of physicians and hospitals, and at the community and national levels.

Physician-patient relations. The pressure to make physicians more cost conscious, to practice more "cost effective" 
medicine, will force them to make decisions that are contrary to the immediate interests of individual patients even though these decisions may be optimal for society as a whole. The conflict can be seen in Figure 3, which shows the marginal (additional) benefits and marginal costs associated with varying amounts of care. The vertical axis is scaled in dollars while the horizontal axis may be thought of as measuring additional tests, prescriptions, days in the hospital, physician visits, and the like for any given medical condition. The downward slope of the marginal benefit curve simply assumes that the additional benefit of additional care gets smaller as the quantity of care increases. Beyond some point (where the curve crosses the horizontal axis), additional care does the patient more harm than good. The marginal cost curve is horizontal under the simplifying assumption that each additional unit of care increases total cost by about the same amount as the preceding unit. To be sure, for any given patient there will always be great uncertainty about the benefit of any particular intervention, and there may be uncertainty about marginal costs as well: these curves should be regarded as average or expected or "best guess" results.

Given the situation portrayed in Figure 3, what is the optimal amount of care? From a social point of view, the optimum is clearly $Q_{1}$, where the marginal benefit is equal to the marginal cost (under the assumption that the marginal cost reflects the value of the resources in some alternative use). If more care than $Q_{1}$ is provided, the additional cost is greater than the additional benefit. If less than $Q_{1}$ is provided, the benefit of additional care is greater than its cost. 
Figure 3

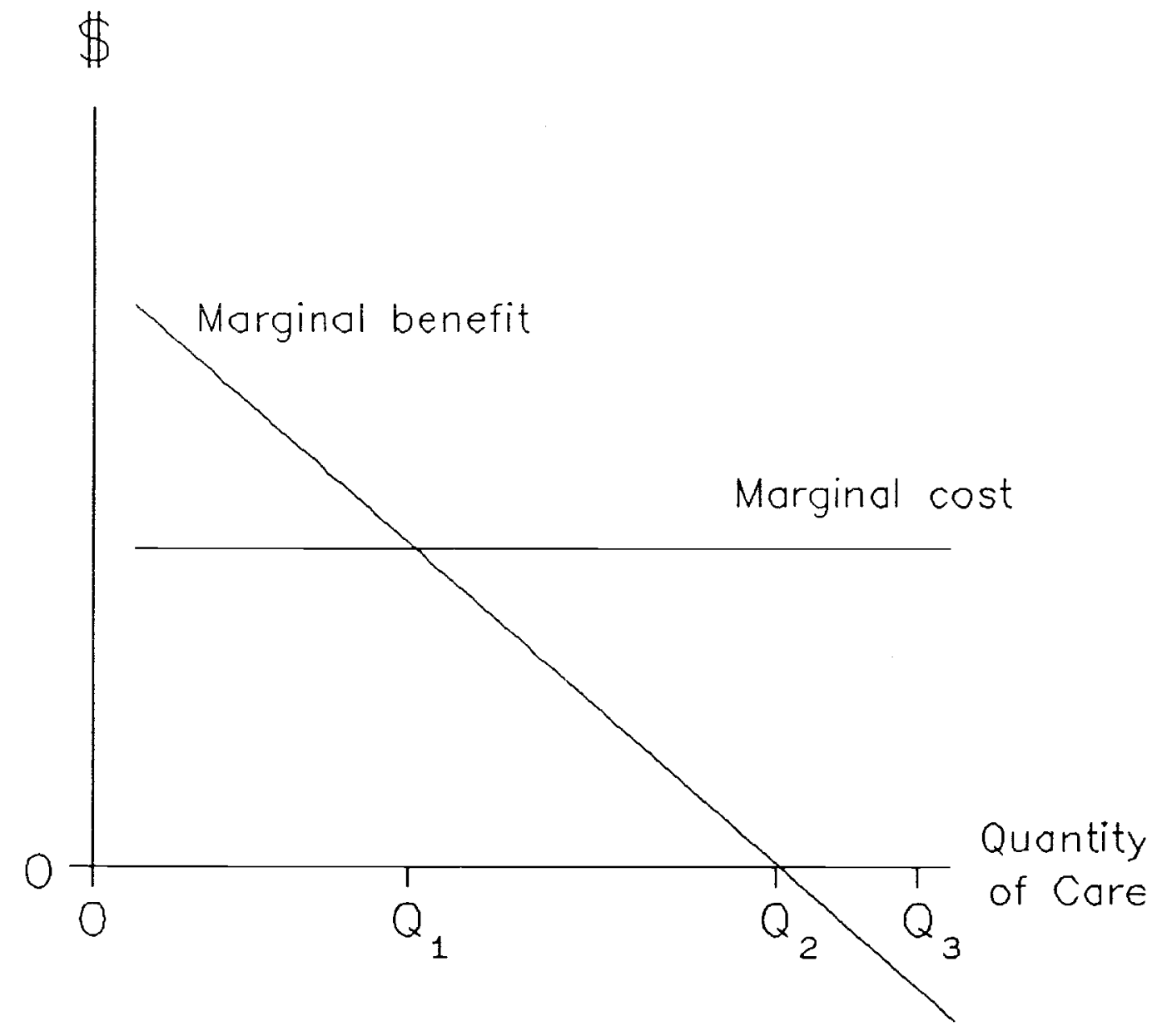

CHOOSING THE "APPROPRIATE" AMOUNT OF CARE 
From the patient's point of view, $Q_{1}$ is best if there is no insurance (i.e., the patient must pay the full marginal cost), but $Q_{2}$ is best if the patient is fully insured. Any pressure on the physician to move from $Q_{2}$ to $Q_{1}$ creates a dilemma: to choose between what is good for society as a whole (and what competitive pressures may require for the survival of his or her group or hospital) and what is best for the individual patient. For instance, the physician may believe that an extra day in the hospital reduces slightly the probability of a complication but that the value of that reduction is far less than the cost of the extra day. Under the old system of reimbursement, the physician had little incentive to discharge the patient a day earlier; the cost of the extra day was widely diffused among all health insurance buyers or all taxpayers. If, however, the hospital is receiving global reimbursement for each admission, or if it is on a prospective global budget, or if the physician belongs to an HMO with capitation reimbursement or to a PPO with utilization controls, there will be considerable pressure on the physician to avoid that extra day of hospitalization.

Assuming the physician chooses $Q_{1}$, what does he or she tell the patient? That $Q_{1}$ is "best"? Or that $Q_{2}$ is better but that $Q_{1}$ is recommended because it is more cost-effective? Most patients follow their physicians' suggestions with regard to tests, hospitalizations, and the like, under the assumption that the physician has a professional commitment to putting the patients' interests first. Confidence in the integrity and intention of the physician frequently makes a positive contribution to the patient's health. If insured patients begin to believe that their 
physician is recommending $Q_{1}$ rather than $Q_{2}$, they may become less honest in describing their symptoms and condition. This loss of candor will make the physician's task more difficult.

To be sure, under the old system there was frequently an economic incentive for the physician to recommend $Q_{3}$, especially for services that produced income for the physician. According to some observers, widespread insurance coverage led some (many?) physicians to recommend $Q_{3}$, which is clearly neither in the best interests of the patient (even if fully insured) or of society. These observers see the current cost containment effort as pushing physicians back from $\mathrm{Q}_{3}$ to $\mathrm{Q}_{2}$. If that is the case, there is no conflict for the ethical physician.

Relations among physicians and hospitals. Compared to most industries relations among physicians and hospitals in the same community have been marked by an unusual degree of cooperation and openness. Although they were ostensibly competing with one another, physicians have freely exchanged information, helped one another, and covered for one another; hospitals, especially the nonprofit community hospitals, have behaved in much the same way. Indeed, one of the complaints of outside observers was that physicians and hospitals did not compete enough. Whatever rivalry existed was largely expressed in efforts to raise the quality of care, leaving the community to pick up the check.

One of the objectives of the new reimbursement methods is to increase competition among physicians and among hospitals, to transform health care into a competitive industry. There are unquestionable advantages to competition, but what will happen to 
the free exchange of information, the cooperation, and the mutual assistance that characterized health care in the past? Will physicians in one group be reluctant to share information with physicians in a competing group? How will physiciaris reconcile profession-wide obligations with obligations to their group and hospital? Will hospitals be willing to make data freely available when this information may give a competitive advantage to another hospital? The virtues of competitive markets are considerable, but it is questionable whether the transformation of the health care industry into an approximation of the used car industry represents social progress. Even if more competition is, on balance, good for society, the health professionals caught in the competitive maelstrom are likely to feel great conflict as to what constitutes appropriate behavior.

Collective responsibility for health care. The citizens of most countries feel a responsibility for meeting the medical care needs of their fellow citizens. In developed countries this is typically done through some form of national health insurance. Altruism is only one motive, to be sure. National health insurance may be desired to eliminate free riders (but the concept of free rider already presupposes an unwillingness to let sick people go without care) or to gain more control over physicians and hospitals, or for other motives.

The United States has never had national health insurance for several reasons. We are more heterogeneous than most nations; we are less sanguine about the beneficence of government; and we have a more comprehensive network of private institutions to pay for health care for those in need. Commity rated insurance 
premiums, for instance, keep insurance affordable for those who use a great deal of care. The heavy users are, in effect, crosssubsidized by those who use less care. Nonprofit hospitals also have typically been an instrument of cross-subsidization. They charge less than full cost to some patients (sometimes charging or collecting nothing at all) while making up the difference through charges to other patients. The pattern of coverage that emerged in the United States in the late 1960s and 1970s was patchy in many respects, but it came closer to providing universal coverage for a single standard of care than anything previously experienced in this country.

The new methods of reimbursement are designed to change this pattern. Competitive purchase of health insurance on a selective basis will erode community rating as groups with low utilization demand and obtain lower premiums. Cross-subsidization by hospitals will be eliminated as competitive buyers refuse to pay more than their true costs.

The normative inferences to be drawn from these changes vary with circumstances and values. For instance, many people believe that if cigarette smokers use more medical care than nonsmokers, it is appropriate that they pay a higher premium for health insurance. But what if old people use more care than the young, women more than men, blacks more than whites, or persons with congenital abnormalities more than those without such limitations? Legislation that prohibits insurance companies from explicitly considering specific characteristics in setting individual premiums do not have much effect. Most insurance is 
bought by groups, and is mostly experience-rated or self-insured. The current trend is for each group to try to get the lowest possible premium for itself regardless of what happens to the rest of the community.

The ethical dilemma is clear. On the one hand it is socially desirable to reward healthy behaviors and efficiency and to punish excessive use of care. On the other hand the fragmentation of insurance markets raises the possibility of very high premiums for some groups. Society could deal with this problem by explicitly subsidizing those groups with high utilization. However, this may be more difficult to accomplish (for political and administrative reasons) than the previous method of implicit subsidies through community-wide or nation-wide premiums. 


\section{What Is to Be_Done?}

For decades various politicians, academicians, health professionals, and policy experts have been offering "solutions" to the problems of health care. Competition, regulation, more government subsidy, less government subsidy, increasing the supply of hospitals and physicians, decreasing the supply--most of these strategies have been adopted at one time or another; none have been or are likely to be "the" solution. Why not? Are they flawed in theory? In execution? Not necessarily. The time has come to candidly acknowledge that some problems defy solution, that the most one can hope for is alleviation and amelioration.

Health policy, like so many other major areas of public concern, requires trade-offs between such highly valued goals as efficiency and justice, and between freedom and security. Even the best solution must fall short in one direction or another, and the more effective the solution is for one goal the greater the shortfall is likely to be for another. That is the principal reason why there is so much controversy over policy: people differ in the values they place on the various goals. Some are prepared to see society give up a good deal of efficiency to get more justice or more security while others feel that freedom is a paramount value.

The financing of health care is a classic example of an insoluble dilemma, the need to choose between the Scylla of risk aversion and the Charybdis of moral hazard. Most people do not 
want to run the risk of having to pay very large bills for medical care. They seek health insurance, but once they have the insurance they consume more medical care than they would without insurance, and more than is socially optimal. The cost of this additional care makes health insurance more expensive than it would otherwise be. All of this is true regardless of whether insurance is obtained privately or provided collectively through government.

A theoretical solution is for individuals, when well, to make an arrangement with the insurance company and/or the providers of care that when sick, only the socially optimal amount of care will be provided, even though the insurance nominally covers all necessary care. Prepaid group practices (such as Kaiser) and the British National Health Service can be regarded as being organized on that prirciple. It works, and sometimes it works very well, but it requires either some deception or a great deal of restraint. It is rational for a person who is well to want to be part of such a system, but once sick it is equally rational to want all the care that might provide some benefit. The challenge to the system is to keep the patient from getting that additional care.

In the past it may not have been too difficult to meet that challenge because much of the additional care delivered in other systems was of questionable value. But as competitive pressures drive all systems toward more stringent evaluation of the costeffectiveness of care, it will become more difficult to convince patients that they are getting the best possible care. "Lowyield" medicine is not "no-yield" medicine. 
One partial solution lies in changing perceptions of what constitutes "appropriate" care. Once the leading medical centers change their approach, and the leading medical schools change what they teach their students, most physicians will adapt to prevailing practice, just as they have in the past. Patients will. then adapt to their physicians' recommendations.

As discussed in the section on ethical concerns, competitive pressures among physicians and hospitals may inhibit the flow of socially useful information. A partial solution to this problem can be found in the approach of other industries. The public utility companies, for instance, sponsor and generously fund the Electric Power Research Institute to conduct long-run economic, social, and technical research that benefits the individual companies and society as a whole. Several highly competitive electronics companies have created a consortium to carry on research on a scale greater than would be possible for the individual firms. The key to such industry undertakings is widespread agreement that all companies will contribute funds, data, personnel, and the like. Such agreement is necessary to keep each company from thinking that cooperation on their part will put them at a competitive disadvantage.

The problem of insuring medical care for all, regardless of their income or other circumstances, is primarily a matter of will, rather than of method of reimbursement. When government agencies simultaneously change their method of paying for care for the elderly or the poor or any other group and reduce the amount they are prepared to pay, there is a high probability that 
there will be some reduction in the quantity or quality of care received. It is usually incorrect, however, to blame the new method for the denial of care; it is the reduction in the amount of money available for reimbursement that is probably the cause. If society wants to provide care for the poor, virtually any system of reimbursement can be used. It is not the change in reimbursement method per se that is denying care to the poor; the change is simply the instrument whereby a weakening of commitment to the poor is given expression.

The situation is, of course, more complicated than that. Much of the pressure for change in reimbursement is not motivated by a desire to see the poor get less care; it is an effort to make the system more cost-effective. If that is the dominant motive, however, there is an urgent need to find ways to halt and reverse the erosion of support for the least fortunate in our society. It seems highly unlikely that this can be accomplished without substantial intervention of government through taxes and subsidies. This need not involve a take-over of medicine by government, or an abandonment of the movement toward more costeffective medicine. If not done in a timely fashion, however, a backlash may develop.

Every revolution carries within it the seeds of its own destruction through excessive preoccupation with one goal. The present revolution in health care finance is no exception. The problems it addresses are palpable: over-utilization of medical services, inadequate evaluation of new technologies, inefficient and inequitable cross-subsidization, excess supplies of specialists and hospital beds. But the problems it may create are 
also significant: inadequate insurance coverage for millions, erosion of professional ethics as an instrument of control, loss of trust between physicians and patients, decrease in activities with large positive externalities. The new challenge is to capture and preserve the benefits of the revolution while minimizing its costs. Now that society has decided it can "call the tune," we must think deeply and carefully about what tune we want the "piper" to play. 


\section{REFERENCES}

Luft, Harold S. 1981. Health Maintenance Organizations:

Dimensions of Performance (New York: John Wiley \& Sons).

Manning, Willard G., Arleen Leibowitz, George Goldberg, William

Rogers, and Joseph P. Newhouse. 1984. "A Controlled Trial

of the Effect of a Prepaid Group Practice on Use of

Services," New England Journal of Medicine 310 (June 7)

$1505-1510$.

Newhouse, Joseph P., Willard G. Manning, Carl N. Morris, Larry L.

Orr, Naihua Duan, Emmett B. Keeler, Arleen Leibowitz, Kent

H. Marquis, M. Susan Marquis, Charles E. Phelps, and Robert

H. Brook. 1981. "Some Interim Results from a Controlled

Trial of Cost Sharing in Health Insurance," New England

Journal of Medicine 305 (December 17) 1501-1507.

Smith, Adam. 1776. The Wealth of Nations (New York: The Modern

Library), 1937 ed., p. 423. 